\title{
Portfolio Selection with respect to the Probabilistic Preference in Variable Risk Appetites: A Double-Hierarchy Analysis Method
}

\author{
Ruitao Gu (D), Qingjuan Chen $(\mathbb{D}$, and Qiaoyun Zhang \\ School of Finance, Southwestern University of Finance and Economics, Chengdu 611130, China \\ Correspondence should be addressed to Qiaoyun Zhang; yun208208208@163.com
}

Received 26 February 2021; Revised 26 March 2021; Accepted 2 April 2021; Published 19 April 2021

Academic Editor: Wei Zhou

Copyright ( $\odot 2021$ Ruitao Gu et al. This is an open access article distributed under the Creative Commons Attribution License, which permits unrestricted use, distribution, and reproduction in any medium, provided the original work is properly cited.

\begin{abstract}
Traditional portfolio selection models mainly obtain the optimized portfolio ratio by focusing on the prices of financial products. However, investors' multiple preferences and risk appetites are also significant factors that should be taken into account. In consideration of these two factors simultaneously, we propose a double-hierarchy model in this paper. Specifically, the first hierarchy quantifies investors' risk appetite based on a historical simulation method and probabilistic preference theory. This hierarchy can be utilized to describe investors' variable risk appetites and ensure the obtained investment ratios meet investors' immediate risk requirements. Then, using the cross-efficiency evaluation principle, the optimal investment ratios can be derived by fusing investors' multiple preferences and risk appetites in the second hierarchy. Lastly, an illustrative example about evaluating the 10 largest capitalized stocks on the Shenzhen Stock Exchange is given to verify the feasibility and effectiveness of our newly proposed model. We make the theoretical contribution to improve the traditional portfolio selection model, especially considering investors' subjective preferences and risk appetite. Moreover, the proposed model can be practical for assisting investors with their investment strategies in real life.
\end{abstract}

\section{Introduction}

Portfolio selection has been broadly discussed in the field of economics over years. As an effective tool to diversify risks and increase profits, how to optimize the portfolio has also become a hot issue for investors. Since optimized portfolios are capable to diversify risks, they can be differently and flexibly changed according to investors' risk appetites. Even though people would mainly concern about the expected returns, some key elements should also be taken into consideration, such as investors' risk appetites and their subjective preference. These two key elements are variable for different investors. Moreover, an investor's risk appetite and preferences can be dynamic in different periods. As a result, they can be impacted by external and internal factors. On the contrary, how to quantitate investors' dynamic risk appetite and multiple preferences is the issue that this paper addresses as well. To optimize portfolio selection from the perspectives of investors' dynamic risk appetites and subjective preferences, this study proposes a double-hierarchy model that considers investors' dynamic risk appetites with probabilistic preference and multiple preferences simultaneously. Furthermore, the feasibility and effectiveness of our newly proposed model are proved by providing an empirical analysis based on the data of China's Shenzhen A-share market.

In the previous studies in the portfolio field, most scholars focus on returns and risks [1], stockholder wealth, asset allocation, and financial product price. However, rational investors would make investment decisions merely based on a single preference such as financial product price. Instead, they tend to consider multiple relative preferences of investment objectives with dynamic risk appetites. In view of that, some scholars propose multipreference models to cope with the above issues. For example, Kwan [2] proposed an optimal algorithm for seven types of multipreference models, which does not need a clear ranking of stocks. Based on this algorithm, Jun [3] proposed that the price of financial products must be considered when considering the least risk and the greatest benefit, and the price also determines the 
weight of the portfolio selection. Chamberlain et al. [4] employed it to calculate the optimal portfolio, enabling investors to amplify across different forms of assets. Other scholars mainly pay attention to portfolio selection, forecast of stock return [5], and so on.

As the medium of investment, portfolio analysis, multipreference analysis, and selection are key factors that cannot be ignored in the financial product market. Therefore, considering multipreference portfolio analysis is also the key to current research. From the perspective of preference analysis, different scholars have carried out research studies on investment portfolio preference selection issues, preference evaluation, and preference effects. This article is mainly based on the cross-efficiency model and selected multiple-preference portfolio model. Previous studies have shown that both single preference and dual preference can affect venture capital to a certain extent. In the classic efficiency evaluation, the biggest difficulty at present is how to choose the aggressive and benevolent. Researchers have started more in-depth research and analysis for this. Mei [6] applied the dual-preference analysis of the portfolio to get a new strategy and obtained a higher rate of return for the first time. Penman and Sougiannis [7] used momentum preference indicators and value preference indicators to analyze market efficiency, and the results showed that they can generate higher profits. Based on their analysis, Paul and Bergin [8] found that the rates of return of the two are independent of each other, and the rates of return have increased, but they are not relevant. Li and Chuang [9]; Reikvam et al. [10]; and Asai \& Mcaleer [11] carry out detailed studies from the perspectives of accuracy, feasibility, and simplicity of preference selection, respectively. Rowley and Kwon [12] analyzed current portfolio preferences from multiple perspectives of immediacy, representativeness, and risk and improved the adaptive level of preference selection. In addition, Xue and Zhou [13] and Israelov and Klein [14] classified the nature of the multipreference indicators; on this basis, Haley [15] studied the heterogeneity in multiplepreference selection and applied the research model to the portfolio in the stock market. They found that due to external effects, indicators with only profitability preferences are not applicable to the portfolio market.

In general, the current investment portfolio preference focuses on investment transaction risk, profitability, and representative indicators. Although the research results are quite abundant, the existing theories are still difficult to match the continuous development of the financial product market investment portfolio. Thus, we use variable multiple preferences to meet the growing portfolio demand.

The above investigations consider some essential elements of the portfolio. However, typical investors will adjust their portfolio selection due to the increase or decrease of their income, the changes of original investment targets, and the vicissitude of the investment macroenvironment. Therefore, this paper introduces several representative factors of investor risk appetite into the portfolio selection model.

Investor risk appetite has been a hot issue in the investment field. It is usually classified into risk-averse, risk-neutral, and risk-seeking. Scholars mainly focus on in the field of pure contagion, commodity returns, and exchange rates [16]. Being different from the traditional qualitative empirical tests, some researchers attempt to research the variable risk appetites of investors [17]. Furthermore, some papers broaden the risk appetite coefficient [18-20]. Smimoua et al. [21] believed that portfolio selection needs to refer to certain preferences. On the basis of these, Smith and Ierapetritou [22] put forward a single evaluation criterion, and Zrs and Bayoumi [23] proposed multiple evaluation criteria for portfolios; both of them are enriching the research content of the portfolio evaluation criterion. In addition, some scholars focus on the venture capital and technological performance by multiple evaluation criteria [24-26]. Investors' risk appetite is also an important research content in the field of investment portfolio. Since Friend and Blume [27] proposed the risk attitude coefficient, firstly, many scholars pay attention to the risk attitude research, and Hansen and Singleton [28] measured the risk attitude coefficient range from 0.68 to 0.97 . Other scholars adopt different data to measure risk attitude coefficient and obtain different ranges; Halek and Eisenhauer [29] measured that the average risk appetite coefficient is 3.735 based on life insurance data. Nosic and Weber [30] found that investors' risk appetites are changeable in the face of diversified financial products; especially, Zhang et al. [5] believed that risk appetites will change with changes in previous returns. Dulleck et al. and Yanling and Dragon [31,32] showed that risk appetites will change in macroeconomic indicators. As a result, we attempt to investigate investors' variable risk appetites and quantify them by using historical simulation and probabilistic preference theory.

As mentioned above, the previous studies mainly focus on a single preference of the portfolio, such as financial product price, but less attention is paid to investors' variable risk appetites. Therefore, we quantify the variable risk appetites and introduce them into a multipreference portfolio selection model to carry out further empirical investigation.

The remainder of this paper is organized as follows: the next section of this paper describes the multiple-preference portfolio selection model (MPPS). Double-hierarchy multiple-preference model (DHMP) will be elucidated in Section 3. Section 4 explains the modeling steps and the illustrated example. Section 5 conducts the empirical study. The fifth part gives conclusions and some research directions. The process is shown in Figure 1.

\section{Multiple-Preference Portfolio Selection Model in the Background of the Probabilistic Preference}

2.1. Preferences and Multiple Preferences. In the financial product market, investors make a choice that whether to select the product in the past mainly based on the current and historical prices of financial products. In other words, portfolio selection is affected by price preference. However, with the financial product market continuing to improve, increasing investors consider multiple preferences. The 


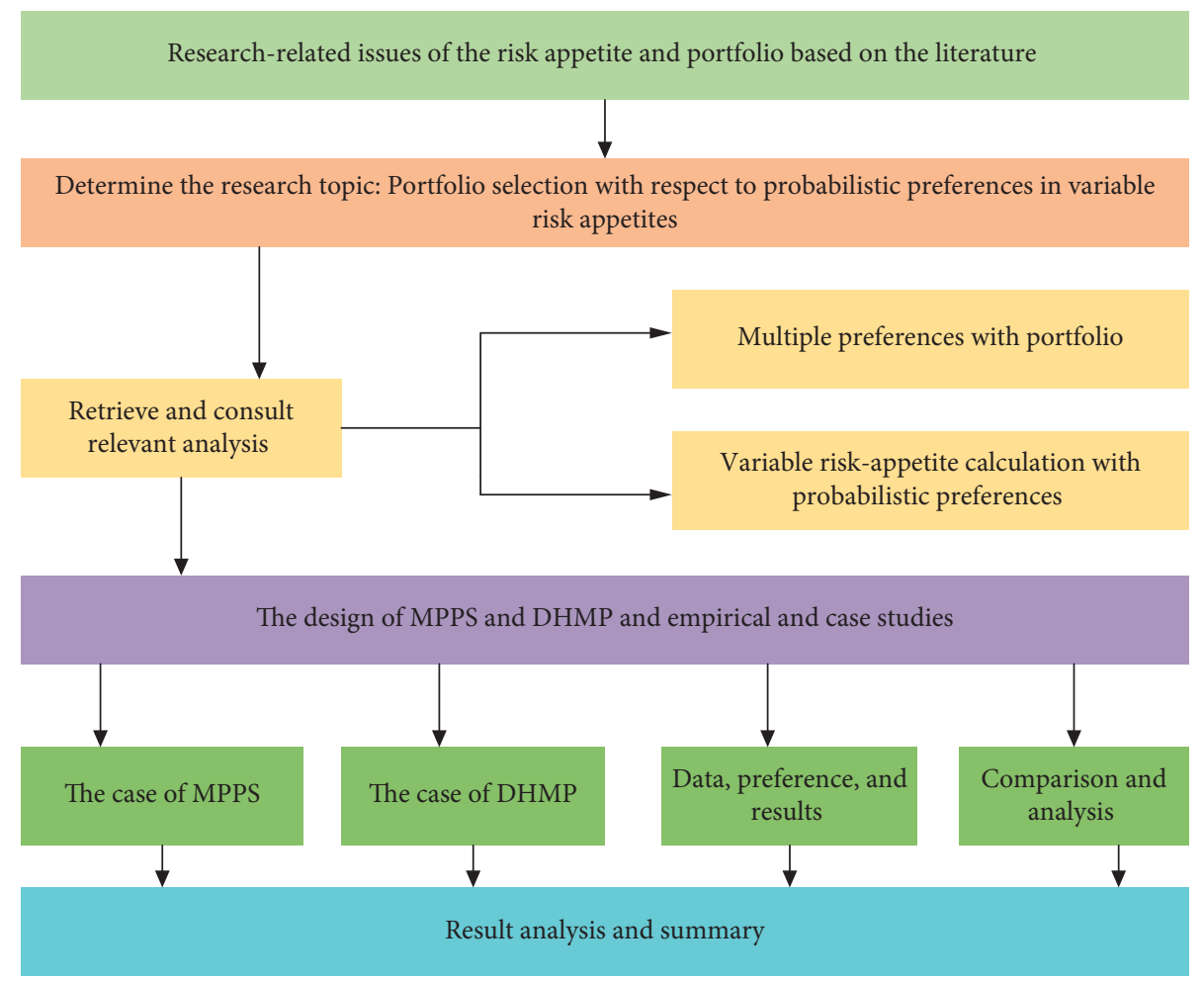

FIgURE 1: The research structure of this paper.

preferences of |products are very wide. From the perspective of return and risk attributes, there are high risk and high return, low risk and low return, and risk-free return. From the perspective of industry attributes, there are high energy consumption, low energy consumption, and green environmental protection. And we analyze the portfolio model from the multiple-preference attributes of returns and risk and measure the preference of financial products from the indicator characteristics of the investment object. Different investment indicators reflect different preferences. Drawing on the cross-efficiency evaluation method, we introduce the inclusion of multiple preferences to conduct the portfolio model.

With the help of efficiency evaluation ideas, we interpret preferences from the perspective of risk and return. When there is a single risk preference in the market, there is only one evaluation unit for investment products, but there are often multiple preferences and multiple decision-making units in practical investment. Through multiple preferences, multiple risks and return issues of investment products can be analyzed clearly, the decision maker does not need to give any subjective information, and there is no need to preset a certain production function.

2.2. Multiple-Preference Portfolio Selection Model and Calculation. Then, we build the multiple-preference portfolio selection in the background of cross-efficiency. Assume that there are $n$ evaluation units. There are $m$ different risk preferences and $s$ return preferences in evaluation units, and the risks and benefit vectors are

$$
X_{j}=\left(x_{1 j}, x_{2 j}, \ldots, x_{m j}\right), Y_{j}=\left(y_{1 j}, y_{2 j}, \ldots, y_{s j}\right) .
$$

For the multiple-preference value $E_{d d}$, we can use the traditional CCR model for calculation:

$$
\begin{aligned}
& E_{d d}=\max \sum_{r=1}^{s} \mu_{r d} y_{r d}, \\
& \text { s.t. }\left\{\begin{array}{l}
\sum_{i=1}^{m} w_{i d} x_{i d}-\sum_{r=1}^{s} \mu_{r d} y_{r j} \geq 0, \quad j=1,2, \ldots, n, \\
\sum_{i=1}^{m} w_{i d} x_{i d}=1, \\
w_{i d} \geq 0, \quad i=1,2, \ldots, m, \\
\mu_{r d} \geq 0, \quad r=1,2, \ldots, s,
\end{array}\right.
\end{aligned}
$$


where $\omega_{i d}(i=1,2, \ldots, m)$ and $\omega_{i d}(i=1,2, \ldots, m)$ represent the weight of risk preferences $x_{i j}$ and return preferences $y_{r j}$. We can get the optimal weight $\omega_{1 d}^{*}, \ldots, \omega_{m d}^{*}, \mu_{1 d}^{*}, \ldots$, $\mu_{s d}^{*}$ of the multiple-preference unit by solving model (2); furthermore, the value of cross-evaluation can be achieved by the following equation:

$$
E_{d j}=\frac{\sum_{r=1}^{s} \mu_{r d}^{*} y_{r j}}{\sum_{i=1}^{m} \omega_{i d}^{*} x_{i j}}, \quad d, j=1,2, \ldots, n .
$$

The cross-evaluation value of the preference unit can be obtained by comparing equations (2) and (3). For every preference unit, all cross-evaluation values $E_{d j}(d=1,2, \ldots$, $n$ ) are averaged by the following equation:

$$
\bar{E}_{j}=\frac{1}{n} \sum_{d=1}^{n} E_{d j}(j=1,2, \ldots, n) .
$$

$\bar{E}_{j}$ is the final efficiency value. In the above equation, the optimal target value of model (2) is unique, but the optimal weight is not unique possibly. Through the calculation of equation (3), we may solve multiple different cross-efficiency preference values; to solve this problem, we build the following equation to form a multiple-preference portfolio selection model:

$$
\begin{gathered}
\beta=o p t \sum_{j=1, j \neq d}^{\delta} \mu_{r d}\left(\sum_{j=1, j \neq d}^{n} y_{r j}\right), \\
\\
\sum_{i=1}^{m} w_{i d} x_{i j}-\sum_{r=1}^{s} \mu_{r d} y_{r j} \geq 0, \quad j=1,2, \ldots, n, \\
\\
\sum_{i=1}^{m} w_{i d}\left(\sum_{j=1, j \neq d}^{n} x_{i j}\right)=1, \\
\quad \sum_{r=1}^{m} \mu_{r d} y_{r d}-\beta_{d d} \sum_{i=1}^{m} w_{i d} x_{i d}=0, \\
w_{i d} \geq 0, i=1,2, \ldots, m, \\
\mu_{r d} \geq 0, r=1,2, \ldots, s, \\
d=1,2, \ldots, n,
\end{gathered}
$$

where $m$ and $s$ represent the standard number of risk preferences and profitable preferences, which are presented as $X_{j}=\left(x_{1 j}, x_{2 j}, \ldots, x_{m j}\right)$ and $Y_{j}=\left(y_{1 j}, y_{2 j}, \ldots, y_{s j}\right)$. $w_{i d}(i=1,2, \ldots, m)$ and $\mu_{\rho d}(\rho=1,2, \ldots, s)$ denote the proportion vector of $x_{i j}$ and $y_{i j}$, respectively. In addition, $\beta_{d d}$ denotes the self-evaluation value, and $\beta_{d j}$ is the cross-evaluation value and calculated by the model.

Then, after we calculate $\beta_{d j}$, take the mean and variance of $\beta_{d j}$. Finally, we take it into using the mean variance model for conducting the multiple-preference portfolio selection model.

$$
\begin{aligned}
& \min \delta\left(R_{P}\right)=\sum \sum x_{i} x_{j} \operatorname{cov}\left(R_{i}-R_{j}\right), \\
& \text { s.t. }\left\{\begin{array}{l}
R_{P}=\sum x_{i} R_{i}, \\
1=\sum x_{i}, \\
\text { or } 1=\sum x_{i}, x_{i} \geq 0,
\end{array}\right.
\end{aligned}
$$

where $\delta\left(R_{P}\right)$ represents the variance of the investor's choice, that is, the risk measure of the overall selection, $\operatorname{cov}\left(R_{i}-R_{j}\right)$ is the covariance of investment products, and $x_{i}$ and $x_{j}$ are the weights of different financial products. In addition, $R_{P}$ is the expected rate of return; we combined multiple preferences and portfolio theory to build a multiple-preference portfolio selection model.

\section{Double-Hierarchy Multiple-Preference Model Based on the Probabilistic Preference}

Based on the multiple preferences, we propose a doublehierarchy multiple-preference model composed of variable risk appetite coefficients based on probabilistic preference and multiple preferences; we first introduce the historical simulation method and probabilistic preference to describe the variable risk appetites, and after the second hierarchy of calculation, the weight of the optimal portfolio is obtained; the process is displayed in Figure 2.

\subsection{First Hierarchy Calculation of the Variable Risk Appetites} in the Probabilistic Preference. In this part, we introduce the interval probabilistic preference as the evidence measure, assume that the probability of occurrence of the event is an interval value, and describe the ambiguity of choice, according to the probability theory $[33,34]$. The preference of investors for the program is described by four types of relationships: surpass $>$, cannot compare, equal $\approx$, worse than $\prec$, and expand to surpass, worse than, equal, incomparable but there is a previous $\vee$, not compare with upper bound $\|_{\wedge}$, cannot compare with upper bound and lower bound $\|_{\wedge}^{\vee}$ cannot compare with unbounded \| \|; we take interval probability theory as a tool for uncertain decisions. Set the program selection problem; the alternatives are $X=\left[A_{1}, \ldots, A_{i}, \ldots, A_{k}, \ldots, A_{m}\right]$, the decision-making group is $E=\left[e_{1}, e_{2}, \ldots, e_{j}, \ldots, e_{n}\right]$, the weight of $e_{j}$ is $w_{j}, \sum_{j=1}^{n} w_{j}=1,1 \geq w_{j} \geq 0, e_{j}$ is the preference relationship and $A_{k}, R=\left\{>,\left\|^{\vee},\right\|_{\wedge}, \|_{\wedge}^{\vee}, \approx\right\}$ is the probability distribution on the interval, and the probability of $A_{i} r A_{k}$ : $q_{j, r}=\left[q_{j, * r}, q_{* j, r}\right]$ and $q_{j, * r} \leq q_{* j, r}, \forall r \in R$.

Determine the objective function of maximizing the probability of the investor's preference relationship with the following formula: 


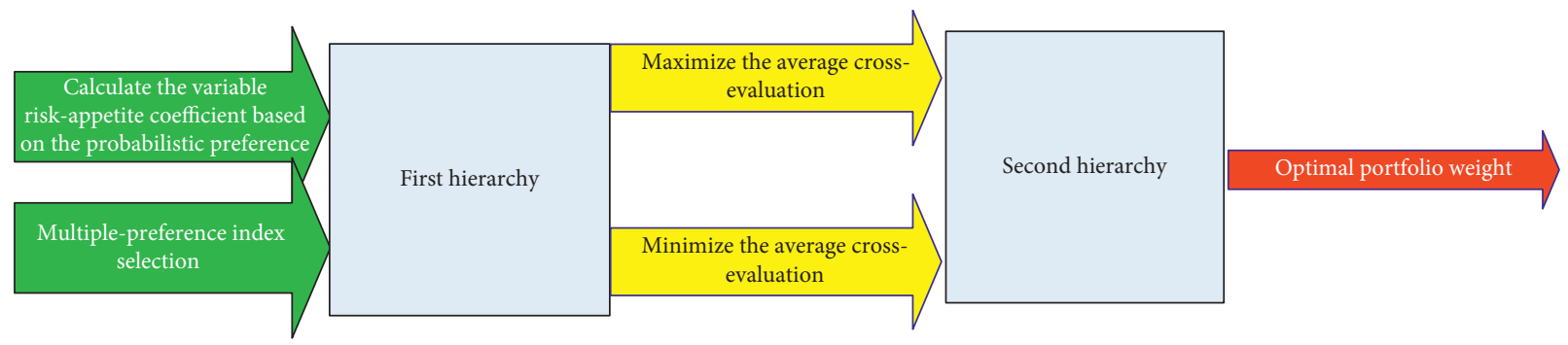

FIGURE 2: The process of the double-hierarchy model with respect to the probabilistic preference.

$$
\begin{aligned}
& \left.\max _{r \in R=\left\{>\|,\|,\|,\| \|_{\wedge}^{\vee}, \approx,<\right\}} Z\right\}=\prod_{j=1}^{n}\left(w_{j} q_{j}, r\right)^{x_{r}}, \\
& \text { s.t. }\left\{\begin{array}{c}
q_{j, * r} \leq q_{j, r} \leq q_{j, * r}, \sum_{r \in R=\left\{>\|,\|,\|,\|\|\| \|_{\wedge}^{v}, \approx,<\right\}} q_{j, r}=1, \quad \forall_{j}=1,2, \ldots, n, \sum_{j=1}^{n} w_{j}=1, \\
\sum_{\substack{v \\
r \in R=\left\{>,\|,\|,\|\|_{\wedge}^{v}, \approx,<\right\}}} x_{r} \geq 1, \quad x_{r}=0,1,
\end{array}\right.
\end{aligned}
$$

where $\prod_{j=1}^{n}\left(w_{j} q_{j}, r\right)^{x_{r}}$ represents the total probability. Determine the collective preference of all schemes in $B$, and get the collective preference by solving model $R^{*}$. Use the binary relationship priority rule to filter and get the preference information about the program. And we take the average of the upper bound and lower bound as the foundation of historical simulation.

Because investors prefer to construct portfolios based on their own risk appetites, after the probabilistic preference calculation, we combine with a historical simulation to describe investors' variable risk appetites. First, investors are provided with some financial products based on their interests. Then, the list of the investors' preferred financial products can be given. Thus, we calculate the variable riskappetite coefficient of investors according to their lists using the following model:

$$
\begin{aligned}
& \max f\left(k_{i}\right)=\max \left(k_{1}+k_{2}+\cdots+k_{n-1}\right) \\
& \text { s.t. }\left\{\begin{array}{l}
E_{\min }+\theta\left(E_{\max }-E_{\min }\right)-E_{\min }^{2}-\theta\left(E_{\max }^{2}-E_{\min }^{2}\right)+a_{1}-b_{1}>0 \\
E_{\min }^{2}+\theta\left(E_{\max }^{2}-E_{\min }^{2}\right)-E_{\min }^{3}-\theta\left(E_{\max }^{3}-E_{\min }^{3}\right)+a_{2}-b_{2}>0 \\
\vdots \\
E_{\min }^{n-1}+\theta\left(E_{\max }^{n-1}-E_{\min }^{n-1}\right)-E_{\min }^{n}-\theta\left(E_{\max }^{n}-E_{\min }^{n}\right)+a_{n-1}-b_{n-1}>0, \\
a_{1} b_{1}=0, a_{2} b_{2}=0, \ldots, a_{n-1} b_{n-1}=0, \\
b_{1}-a_{1} k_{1} \geq 0, b_{2}-a_{2} k_{2} \geq 0, \ldots, b_{n-1}-a_{n} k_{n-1} \geq 0, \\
a, b \geq 0, \theta \in[0,1], k_{i} \in\{0,1\}, i=1, \ldots, n-1,
\end{array}\right.
\end{aligned}
$$

where $E_{\max }$ and $E_{\min }$ are the optimization results calculated by models (9) and (10), respectively, which stand for the highest profitable risk matrix and the lowest one, $k$ is nonnegative and $k \in\{0,1\}, n$ is the number of portfolio choices, and $\theta$ is the variable risk-appetite coefficient and $\theta \in[0,1]$. Besides, $a$ and $b$ are the slack variables, and $a, b \geq 0$.

We can find that investors should provide a rank for $n$ objectives first, and then their variable risk appetites can be calculated by this model. For example, if there are four stocks, $A, B, C$, and $D$, an investor gives his/her rank based on his/her subjective evaluation, such as $\mathrm{A} \geq \mathrm{B} \geq \mathrm{C} \geq D$. Then, we use models (8) and (9) to calculate $E_{\min }$ and $E_{\max }$, respectively, and derive the variable risk-appetite parameter $\theta$ based on model (8).

3.2. Second Hierarchy Fusion of Probabilistic Preferences and Variable Risk Appetites. To fuse the above variable risk 
appetite and calculate the optimal investment ratios, we build a multipreference portfolio selection model on the basis of the idea of cross-efficiency [35]. The model can assess financial products with multiple preferences and provide portfolio selection. Moreover, the weights of different financial products in a portfolio and the efficient frontier can be calculated by the following models:

$$
\begin{aligned}
& E_{\max }=\max \sum_{j=1, j \neq d}^{s} \mu_{r d}\left(\sum_{j=1, j \neq d}^{n} y_{r j}\right), \\
& \text { s.t. }\left\{\begin{array}{l}
\sum_{i=1}^{m} \omega_{i d} x_{i j}-\sum_{r=1}^{s} \mu_{r d} y_{r j} \geq 0, \quad j=1,2, \ldots, n, \\
\sum_{i=1}^{m} \omega_{i d}\left(\sum_{j=1, j \neq d}^{n} x_{i j}\right)=1, \\
\sum_{r=1}^{s} \mu_{r d} y_{r d}-E_{d d} \sum_{i=1}^{m} \omega_{i d} x_{i d}=0, \\
\omega_{i d} \geq 0, \quad i=1,2, \ldots, m, \\
\mu_{r d} \geq 0, \quad r=1,2, \ldots, s, \\
d=1,2, \ldots, n,
\end{array}\right. \\
& E_{\min }=\min \sum_{j=1, j \neq d}^{s} \mu_{r d}\left(\sum_{j=1, j \neq d}^{n} y_{r j}\right), \\
& \text { s.t. }\left\{\begin{array}{l}
\sum_{i=1}^{m} \omega_{i d} x_{i j}-\sum_{r=1}^{s} \mu_{r d} y_{r j} \geq 0, \quad j=1,2, \ldots, n, \\
\sum_{i=1}^{m} \omega_{i d}\left(\sum_{j=1, j \neq d}^{n} x_{i j}\right)=1, \\
\sum_{r=1}^{s} \mu_{r d} y_{r d}-E_{d d} \sum_{i=1}^{m} \omega_{i d} x_{i d}=0, \\
\omega_{i d} \geq 0, \quad i=1,2, \ldots, m, \\
\mu_{r d} \geq 0, \quad r=1,2, \ldots, s, \\
d=1,2, \ldots, n,
\end{array}\right.
\end{aligned}
$$

where $m$ and $s$ represent the numbers of assessed risky and profitable variables, which are presented as $X_{j}=\left(x_{1 j}, x_{2 j}\right.$, $\left.\ldots, x_{m j}\right)$ and $Y_{j}=\left(y_{1 j}, y_{2 j}, \ldots, y_{s j}\right)$, and $\omega_{l d}(\iota=1,2$, $\ldots, m)$ and $\mu_{\rho d}(\rho=1,2, \ldots, s)$ denote the proportion vector of $x_{i j}$ and $y_{i j}$, respectively. In addition, $E_{d d}$ denotes the self-evaluation value, $E_{d j}$ is the cross-evaluation value, and it can be calculated by $E_{d j}=\sum_{r=1}^{s} \mu_{r d} y_{r j} / \sum_{i=1}^{m} \omega_{i d} x_{i j}$, $E_{\max }$ is obtained based on the benevolent strategy to maximize the average cross-evaluation value of each variable, and $E_{\min }$ is obtained based on the aggressive strategy to minimize the average cross-evaluation value of each variable.

By integrating models (9) and (10) with the variable riskappetite coefficient $\theta$, we construct the multipreference portfolio selection model, namely, model (11).

Based on model (11), we can use matrix $z$ to calculate two statistic preferences similar to the price's mean and variance preferences. We can find that $z$ is fused by multiple preferences and variable risk appetites, based on which we can obtain the optimal investment ratios and get the portfolio by using the traditional portfolio model. Clearly, the calculated optimal investment ratios are calculated on the basis of the investor's variable risk appetites and multiple relative preferences.

$$
\begin{aligned}
& z=\theta \max \sum_{j=1, j \neq d}^{s} \mu_{r d}\left(\sum_{j=1, j \neq d}^{n} y_{r j}\right)+(1-\theta) \min \\
& \sum_{j=1, j \neq d}^{s} \mu_{r d}\left(\sum_{j=1, j \neq d}^{n} y_{r j}\right), \\
& \text { s.t. }\left\{\begin{array}{l}
\sum_{i=1}^{m} \omega_{i d} x_{i j}-\sum_{r=1}^{s} \mu_{r d} y_{r j} \geq 0, \quad j=1,2, \ldots, n \\
\sum_{i=1}^{m} \omega_{i d}\left(\sum_{j=1, j \neq d}^{n} x_{i j}\right)=1 \\
\sum_{r=1}^{s} \mu_{r d} y_{r d}-E_{d d} \sum_{i=1}^{m} \omega_{i d} x_{i d}=0 \\
\omega_{i d} \geq 0, \quad i=1,2, \ldots, m \\
\mu_{r d} \geq 0, \quad r=1,2, \ldots, s \\
d=1,2, \ldots, n .
\end{array}\right.
\end{aligned}
$$

\section{Portfolio Selection with respect to Probabilistic Preference Steps and Illustrated Examples}

In this section, we combine the definitions to model and make a multiple-preference selection case. This case is about a program that the investment agencies can prepare for their customers, which is applied to verify the validity and practicality of the MPPS and DHMO models. Subsequently, more in-depth analyses prove the effectiveness of the method in the article.

First of all, we give the risk and profitability indicators in multiple preferences, which mainly have the following properties: the number of risk indicators and profitability indicators in multiple preferences does not need to be equal, and multiple risks can be compared to multiple profitability. It can also be more risky versus less profitable; multiple-preference indicators should fully reflect risk and profitability. Risk indicators and profitability indicators are given in the form of a matrix. If much preference information is displayed in the matrix, then the weights of the multiple-preference portfolio model can also have multiple preferences because multiple portfolio models contain all the preference information; the above criteria can be summarized in Algorithm 1.

Furthermore, the reason we normalize and correct the multiple efficiencies is that (1) normalizing the efficiency value simplifies the complexity of the calculation process; (2) eliminating outliers helps to ensure the stability and accuracy of the results of multipreference portfolios. In addition, 
Step 1: give the fundamental elements $X_{j}=\left(x_{1 j}, x_{2 j}, \ldots, x_{m j}\right)$ and $Y_{j}=\left(y_{1 j}, y_{2 j}, \ldots, y_{s j}\right)$

Step 2: normalize them, put $X_{j}$ and $Y_{j}$ in 0 and 1 , and calculate the value of CCR by $\max \sum_{r=1}^{s} \mu_{r d} y_{r d}$, which is denoted with $E_{d d}(i, j=1,2, \ldots, n)$

Step 3: correct the CCR efficiency value $E_{i i}$ and put it into the cross-efficiency value evaluation $\bar{E}_{d d}$; this process mainly eliminates outliers

Step 4: according to the equation $1 / n \sum_{d=1}^{n} E_{d j}, \operatorname{var}\left(\bar{E}_{d d}\right)$, the multiple preferences that contain the mean and variance of the efficiency value will be found

Step 5: select the Markowitz portfolio model that allows short selling or does not allow short selling, and the optimal weight will be calculated by running software (software used by the authors is MATLAB)

Step 6: if one needs to visually see the results that include the effective frontier of the portfolio, click on software to get the effective frontier map

Algorithm 1: Multiple-preference portfolio selection model.

taking the CCR value first is also to ensure the validity of the multipreference analysis; if the abnormal value of the efficiency value is not eliminated, the error of results easily increases. To comprehensively display the process of MPPS, a simple example of the algorithm is given as follows.

Example 1. The MPPS model is used to obtain the efficiency value with multiple preferences based on the existing information. For example, we can assume that the existing information matrix of MPPS is $Q_{i}$ and $Q_{o}$, and the specific form is as follows:

$$
\bar{Q}_{i}=\left[\begin{array}{cccc}
1 & 1 / 8 & 1 / 4 & 1 / 5 \\
1 / 8 & 1 & 1 / 3 & 1 / 6 \\
1 / 4 & 1 / 3 & 1 & 1 / 5 \\
1 / 5 & 1 / 6 & 1 / 5 & 1
\end{array}\right], \ldots \bar{Q}_{o}=\left[\begin{array}{cccc}
1 & 1 / 7 & 1 / 3 & 1 / 4 \\
1 / 7 & 1 & 1 / 3 & 1 / 6 \\
1 / 3 & 1 / 3 & 1 & 1 / 4 \\
1 / 4 & 1 / 6 & 1 / 4 & 1
\end{array}\right] .
$$

Step 1: mark the MPPS multipreference risk matrix,

$$
\bar{Q}_{i}=\left[\begin{array}{cccc}
1 & 0.13 & 0.25 & 0.20 \\
0.13 & 1.00 & 0.33 & 0.17 \\
0.25 & 0.33 & 1.00 & 0.20 \\
0.20 & 0.17 & 0.20 & 1.00
\end{array}\right]
$$

and multipreference profit matrix,

$$
\bar{Q}_{o}=\left[\begin{array}{cccc}
1 & 0.13 & 0.25 & 0.20 \\
0.13 & 1.00 & 0.33 & 0.17 \\
0.25 & 0.33 & 1.00 & 0.20 \\
0.20 & 0.17 & 0.20 & 1.00
\end{array}\right] \text {. }
$$

Step 2: solve the multiple-preference self-evaluation efficiency value and average cross-efficiency matrix:

$$
\bar{Q}_{E}=\left[\begin{array}{cccc}
1 & 0.0182 & 0.0825 & 0.0500 \\
0.0182 & 1 & 0.1089 & 0.0289 \\
0.0825 & 0.1089 & 1 & 0.0289 \\
0.0500 & 0.0289 & 0.0500 & 1
\end{array}\right], \bar{E}=\left[\begin{array}{llll}
0.2822 & 0.2877 & 0.2890 & 0.3104
\end{array}\right] .
$$

Step 3: give the multiple-preference optimal ranking: rank $=\left[\begin{array}{llll}4 & 1 & 2 & 3\end{array}\right]$.
Step 4: calculate the variance and covariance matrix of $\bar{Q}_{E}: \operatorname{var}\left(\bar{Q}_{E}\right), \operatorname{cov}\left(\bar{Q}_{E}\right)$.

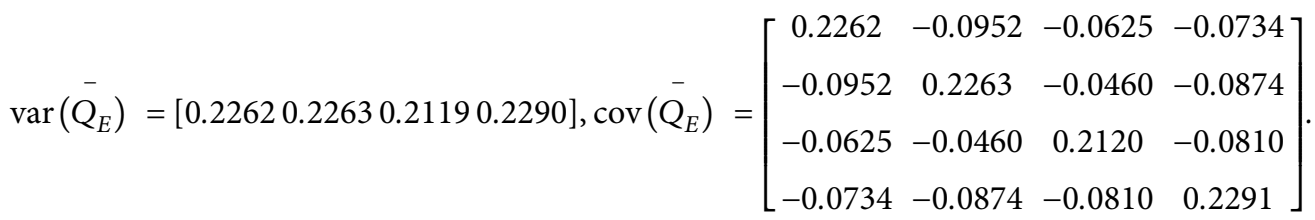

Step 5: it is easy to make a portfolio by using the mean and covariance of efficiency.
According to the above equation, the MPPS multi ple-preference matrix can be obtained; however, when we 
select a portfolio by MPPS, if the variance and covariance matrix are negative definite, we need to change them to positive definite. To clearly demonstrate the last process of MPPS, we would like to take a case in point.

Assume we have three bonds $(A, B, C)$, their expected return Exp Return $=\left[\begin{array}{lll}0.12 & 0.21 & 0.16\end{array}\right]$, and the expected covariance:

$$
\text { Cov Covariance }=\left[\begin{array}{ccc}
0.0100 & -0.0061 & 0.0042 \\
-0.0061 & 0.04000 & -0.0252 \\
0.0042 & -0.0252 & 0.0225
\end{array}\right] .
$$

Select 10 security portfolios among them, draw a risk-return curve, and generate an effective boundary.

It is easy for us to get the effective frontier by running the MPPS: the set of best advantages of the portfolio forms an effective frontier curve in Figure 3. The abscissa represents the variance, and the ordinate represents the expected revenue. In addition, the algorithm of MPPS also gives the expected return under ten different security portfolio forms, and investors can choose their own preferences according to different security portfolio forms; the details are shown in Table 1.

As mentioned previously, we need to connect the investor's risk-appetite coefficient and multiple preferences, build a double-hierarchy portfolio model, and analyze portfolio selection clearly. Therefore, in the process of solving the variable risk-preference coefficient, we also give a simple case to illustrate the effectiveness of the model solution in Algorithm 2.

We can get $\lambda_{1}=[0.5,0.6,0.7]^{T}$ and $\lambda_{2}=[0.8,0.9,1.5]^{T}$. Then, we can establish the following equation:

$$
\begin{aligned}
& \max f\left(k_{i}\right)=\max \left(k_{1}+k_{2}+\cdots+k_{n-1}\right) \\
& \text { s.t. }\left\{\begin{array}{l}
E_{\min }+\theta\left(E_{\max }-E_{\min }\right)-E_{\min }^{2}-\theta\left(E_{\max }^{2}-E_{\min }^{2}\right)+a_{1}-b_{1}>0, \\
E_{\min }^{2}+\theta\left(E_{\max }^{2}-E_{\min }^{2}\right)-E_{\min }^{3}-\theta\left(E_{\max }^{3}-E_{\min }^{3}\right)+a_{2}-b_{2}>0, \\
\vdots \\
E_{\min }^{n-1}+\theta\left(E_{\max }^{n-1}-E_{\min }^{n-1}\right)-E_{\min }^{n}-\theta\left(E_{\max }^{n}-E_{\min }^{n}\right)+a_{n-1}-b_{n-1}>0, \\
a_{1} b_{1}=0, \\
a_{2} b_{2}=0, \\
\vdots \\
a_{n-1} b_{n-1}=0 \\
b_{1}-a_{1} k_{1} \geq 0, \\
b_{2}-a_{2} k_{2} \geq 0, \\
\vdots \\
b_{n-1}-a_{n} k_{n-1} \geq 0, \\
a, b \geq 0, \theta \in[0,1] \\
k_{i} \in\{0,1\}, i=1, \ldots, n-1,
\end{array}\right.
\end{aligned}
$$$$
\begin{aligned}
& \max k=k_{1}+k_{2}+k_{3} \\
& \qquad\left\{\begin{array}{l}
0.5-0.8 * x+a_{1}-b_{1}=0, \\
0.6+0.9 * x+a_{2}-b_{2}=0, \\
0.7+1.5 * x+a_{3}-b_{3}=0, \\
a_{1} * b_{1}=0, \\
a_{2} * b_{2}=0, \\
a_{3} * b_{3}=0, \\
a_{1}-b_{1} * k_{1}>0, \\
a_{2}-b_{2} * k_{2}>0, \\
a_{3}-b_{3} * k_{3}>0, \\
a_{1}>=0, \\
a_{2}>=0, \\
a_{3}>=0, \\
b_{1}>=0, \\
b_{2}>=0, \\
b_{3}>=0 \\
x>=0 \\
x<=1 .
\end{array}\right.
\end{aligned}
$$

We calculate the appetite coefficient $\theta=0.65$ based on the above equation; as long as investors make a choice, we can calculate the variable risk-preference coefficient through historical simulation and probabilistic preference.

\section{Empirical Study of the Double-Hierarchy Model with respect to the Probabilistic Preference}

5.1. Data and Results. To prove the feasibility of the double-hierarchy model, in this section, the 10 largest capitalized stocks on the Shenzhen Stock Exchange that have just been listed for one year are selected as the research objectives. Due to the insufficient data and incomplete investment information of these stocks, the traditional portfolio selection methods cannot be utilized in this situation. Instead, the proposed double-hierarchy model that combines variable risk appetites in the probabilistic preference and multiple-preference indicators is more suitable to address this issue. This model uses data from the Shenzhen $A$-share market and eliminates stocks with incomplete information (see Table 3).

In terms of investors' preference, an example of 4 stocks, $A_{1}, A_{2}, A_{3}$, and $A_{4}$, is listed as $A_{4} \geq A_{3} \geq A_{2} \geq A_{1}$ or in other 


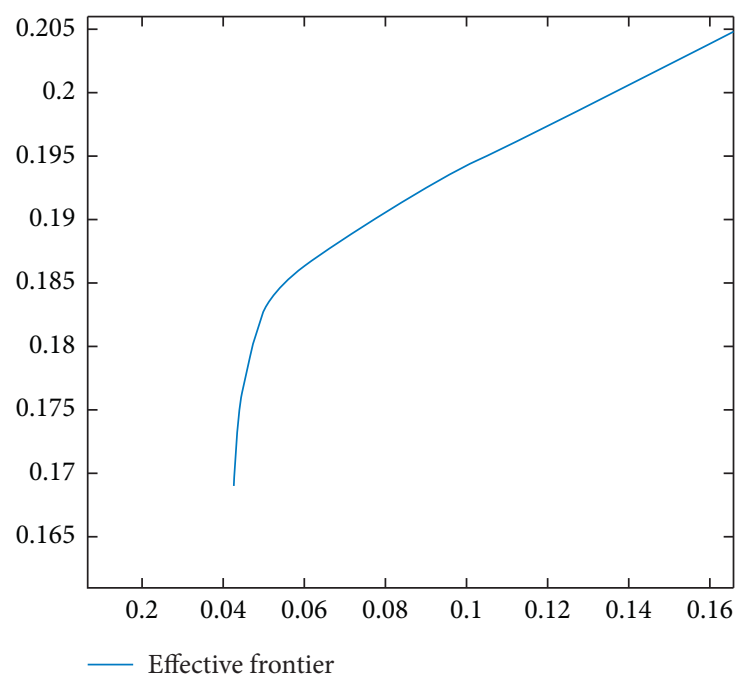

FIGURE 3: The effective frontier of MPPS.

TABLE 1: Ten security portfolio forms' expected rate of return and risk.

\begin{tabular}{lcccccccccc}
\hline Security & 1 & 2 & 3 & 4 & 5 & 6 & 7 & 8 & 9 & 10 \\
\hline portrisk & 0.043 & 0.043 & 0.043 & 0.043 & 0.044 & 0.045 & 0.045 & 0.046 & 0.047 & 0.049 \\
portreturn & 0.169 & 0.170 & 0.172 & 0.173 & 0.175 & 0.176 & 0.178 & 0.179 & 0.180 & 0.182 \\
\hline
\end{tabular}

Step 1: provide the portfolio of different types about financial products for investors, and investors will make their choice according to their own risk and return preferences. Investment program: $A_{1}, A_{2}, A_{3}, \ldots, A_{n}$, investors can choose $n$ rankings according to their preferences, and this ranking includes all financial products we provided.

Step 2: calculate $E_{\max }$ and $E_{\min }$ based on models (3) and (4) simultaneously.

Step 3: calculate the appetite coefficient. We can obtain $E_{\max }$ and $E_{\min }$ after merging similar items based on the investor's choice; then, $\lambda_{1}=\left[a_{1}, a_{2}, \ldots, a_{n}\right]$ and $\lambda_{2}=\left[b_{1}, b_{2}, \ldots, b_{n}\right]$.

Step 4: take $\lambda_{1}$ and $\lambda_{2}$ into model (2) based on software, and we will get the appetite coefficient conveniently.

Step 5: to clearly calculate the appetite coefficient $\theta$, like Step 3, we assume that there are four financial products to choose, allowing investors to choose between financial products' risks and returns according to model (8), and get the result in Table 2.

Algorithm 2: Risk-appetite coefficient model by historical simulation and probabilistic preference.

TABLE 2: The preference information of the expert on $A$.

\begin{tabular}{lcccccccc}
\hline Investor & $\succ$ & $\|$ & $\|^{\vee}$ & $\|_{\wedge}$ & $\|_{\wedge}^{\vee}$ & $\approx$ & $<$ & Average \\
\hline 1 & {$[0.4,0.9]$} & {$[0.6,0.7]$} & {$[0.8,0.5]$} & {$[0.2,1.1]$} & {$[0.5,0.8]$} & {$[0.7,0.6]$} & {$[0.3,1.0]$} & {$[0.5,0.8]$} \\
2 & {$[0.1,0.9]$} & {$[1.1,0.9]$} & {$[0.7,0.8]$} & {$[0.5,1.0]$} & {$[0.4,0.6]$} & {$[0.6,0.9]$} & {$[0.8,1.2]$} & {$[0.6,0.9]$} \\
3 & {$[0.8,2.1]$} & {$[0.6,0.9]$} & {$[0.4,1.6]$} & {$[1.0,1.4]$} & {$[0.7,1.5]$} & {$[1.1,0.8]$} & {$[0.3,0.7]$} & {$[0.7,1.5]$} \\
\hline
\end{tabular}

TABle 3: Summary of example data.

\begin{tabular}{lc}
\hline Stock code & Name \\
\hline 000038.SZ & Shenzhen Capstone Industrial Co., Ltd. \\
000156.SZ & Wasu Media Holding Co., Ltd. \\
000607.SZ & Holley Pharmaceuticals (Chongqing) Co., Ltd. \\
000665.SZ & Hubei Radio \& Television Information Network Co., Ltd. \\
000673.SZ & Contemporary Eastern Investment Co., Ltd. \\
$000681 . S Z$ & Visual China Group Co., Ltd. \\
000719.SZ & Central China Land Media Co., Ltd. \\
000793.SZ & Huawen Media Group \\
000802.SZ & Miracle in June (Beijing) Culture Media Co., Ltd. \\
$000839 . S Z$ & CITIC Guoan Information Industry Co., Ltd. \\
\hline
\end{tabular}


TABLe 4: Multipreference attributes and indices.

\begin{tabular}{lc}
\hline Multipreference attribute & Index \\
The risk preference variables & Inventory turnover \\
& Current ratio \\
& Quick ratio \\
\hline & Earnings per share growth ratio \\
The profitability preference variables & Net income growth rate \\
& Return on assets \\
\hline
\end{tabular}

TABLe 5: Empirical results of the illustrated example.

\begin{tabular}{|c|c|c|c|c|c|c|c|c|c|c|c|c|c|c|c|c|c|c|c|c|c|c|}
\hline \multirow{2}{*}{$\begin{array}{l}\text { Stock codes } \\
000038 . S Z \\
\end{array}$} & \multicolumn{10}{|c|}{ Weight (portfolio with a risk appetite coefficient of 0.5 ) } & \multirow{2}{*}{$\begin{array}{c}\text { Mean } \\
0.11\end{array}$} & \multicolumn{10}{|c|}{$\begin{array}{l}\text { Weight (portfolio with a risk appetite coefficient } \\
\text { of } 0 \text { ) }\end{array}$} & \multirow{2}{*}{$\begin{array}{c}\text { Mean } \\
0\end{array}$} \\
\hline & 0 & 0 & & 0 & & 0 & & 0 & 0 & & & 0 & 0 & & 0 & & 0 & & & 0 & & \\
\hline 00156.SZ & ( & 0 & & 4 & & 0 & & 0 & 0 & & & 0 & 0 & & & & 0 & & & 0 & 0.68 & 0 \\
\hline 006 & ( & 0 & & c & & 0 & & c & 0 & & & 0 & 0 & & 0.0 & & c & & & 0 & 0.69 & 0.04 \\
\hline 0006 & 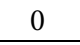 & 0 & & & & 0 & & 0 & 0 & & & 0 & 0 & & 0.0 & & c & & & & 0.7 & 0.21 \\
\hline SZ & & & 0 & & 025 & .08 & & 0 & 0 & & & 0 & 0 & & 0.1 & & 0 & & & 0 & 0.71 & 0 \\
\hline SZ & & .28 & 0 & & & & & & 0 & 007 & & 0 & 0 & & & & c & & & & & 0 \\
\hline & & 0 & 0 & & & 0 & & & & 0 & & 0 & 0 & & & & c & & & & & 0.11 \\
\hline 000793.SZ & & 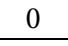 & 0 & & 0.05 & & 0 & & 0 & 0 & & 0 & 0 & & & & 0 & & & 0 & & 0 \\
\hline $00802 . S Z$ & 0.25 & 0 & 0 & 0 & 0.12 & 0.57 & 0 & 0.06 & 0 & 0 & & 0 & 0 & $\Omega$ & & & 0 & & & 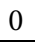 & 0.75 & 0 \\
\hline 000839.SZ & 0 & 0 & 0 & 0 & 1 & 0 & 0 & 0 & 0 & 0 & 0.18 & 0 & 0 & 0 & 1 & & 0 & 0 & & & 0 & 0.64 \\
\hline
\end{tabular}

Weight (portfolio with a risk appetite coefficient of 1) Mean Weight (portfolio with a risk appetite coefficient Mean of 0.47 )

\begin{tabular}{|c|c|c|c|c|c|c|c|c|c|c|c|c|c|c|c|c|c|c|c|c|c|c|}
\hline 000038.SZ & 0 & 0 & 0 & 0 & 0.15 & 0 & 0.25 & 0.06 & 0 & 0.55 & 0.1 & 0 & 0 & 0.27 & 0 & 0 & 0 & 0.34 & 0 & 0 & 0.39 & 0 \\
\hline 000156.SZ & 0 & 0 & 0 & 0 & 0.24 & 0 & 0.31 & 0 & 0 & 0.45 & 0.05 & 0 & 0 & 0.2 & 0.01 & 0.05 & 0 & 0.32 & 0 & 0 & 0.41 & 0.08 \\
\hline 000607.SZ & 0 & 0.14 & 0.05 & 0 & 0.24 & 0 & 0.28 & 0 & 0 & 0.3 & 0.04 & 0 & 0.08 & 0.19 & 0.1 & 0.01 & 0 & 0.24 & 0 & 0 & 0.39 & 0.11 \\
\hline 000665.SZ & 0 & 0 & 0.15 & 0.04 & 0.23 & 0.08 & 0.27 & 0 & 0 & 0.23 & 0.03 & 0 & 0.12 & 0.16 & 0.17 & 0 & 0 & 0.17 & 0 & 0 & 0.39 & 0.18 \\
\hline 000673.SZ & 0.02 & 0 & 0.22 & 0.16 & 0 & 0.13 & 0.08 & 0.09 & 0.21 & 0.1 & 0.24 & 0 & 0.15 & 0.13 & 0.24 & 0 & 0 & 0.1 & 0 & 0 & 0.38 & 0.01 \\
\hline 000681.SZ & 0.22 & 0.26 & 0 & 0.09 & 0.1 & 0.1 & 0 & 0.2 & 0 & 0.02 & 0.16 & 0 & 0.18 & 0.1 & 0.31 & 0 & 0 & 0.03 & 0 & 0 & 0.38 & 0 \\
\hline 000719.SZ & 0.23 & 0.05 & 0 & 0 & 0.04 & 0.39 & 0 & 0.26 & 0 & 0.03 & 0.12 & 0 & 0.25 & 0.04 & 0.35 & 0 & 0 & 0 & 0 & 0 & 0.36 & 0.12 \\
\hline 000793.SZ & 0.25 & 0 & 0 & 0 & 0.13 & 0.43 & 0 & 0.19 & 0 & 0 & 0.08 & 0 & 0 & 0 & 0.45 & 0 & 0 & 0 & 0.1 & 0 & 0.44 & 0.17 \\
\hline 000802.SZ & 0.24 & 0 & 0 & 0 & 0.29 & 0.45 & 0 & 0.02 & 0 & 0 & 0.02 & 0 & 0 & 0 & 0.16 & 0 & 0 & 0 & 0.56 & 0 & 0.27 & 0 \\
\hline 000839.SZ & 0 & 0 & 0 & 0 & 1 & 0 & 0 & 0 & 0 & 0 & 0.17 & 0 & 0 & 0 & 0 & 0 & 0 & 0 & 1 & 0 & 0 & 0.34 \\
\hline
\end{tabular}

relations. After that, the minimum value $\mathrm{E}_{\min }$ and the maximum value $E_{\max }$ can be calculated by models (7)-(9). It is assumed that their maximum values are $0.8,0.9,1.5$, and 0.5 , and the minimum values are $0.5,0.6,0.7$, and 0.8 , respectively. Then, based on probabilistic preference theory (model (7)), we can obtain a corresponding risk-appetite coefficient of 0.47 .

In Table 4, the risk preference variables are the inventory turnover, the current ratio, and the quick ratio, and the profitability preference variables are the earnings per share growth ratio, the net income growth rate, and the return on assets. In this example, we choose these preference indicators because they are broadly applied in the investment field, which can reflect the characteristics of our model.

We can calculate the double-hierarchy model and obtain the results as shown in Table 5. Several conclusions are derived according to the empirical result: (1) each row gives the optimal portfolio selection, and the corresponding proportion of capital investment can be seen in Figure 4, which gives investors a more detailed investment suggestion. (2) Investors can make suitable and dynamic decisions in consideration of their variable investment risk appetites.

5.2. Portfolio Comparison in Different Risk Appetites Calculated by the Probabilistic Preference. In this section, we compared the portfolio effective frontiers under four different risk appetites and multiple preferences and compared the results of the double-hierarchy portfolio with risk and return.

Figure 5 displays the portfolio effective frontiers about the appetites of $0.5,0,1$, and 0.47 . It is easy to see that the efficient frontier of investors synchronous changes with the investor's appetite; in addition, the frontier slows down as the value of risk appetite decreases.

Figures 4 and 6 are the results calculated by the proposed double-hierarchy model, which present the minimum variance set based on four different risk appetites. In addition, we calculate and compare the average weight of the 


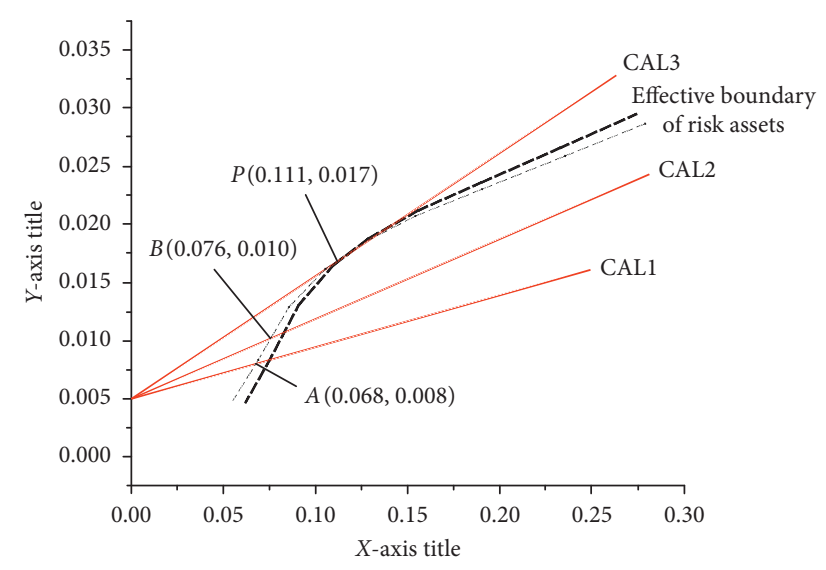

(a)

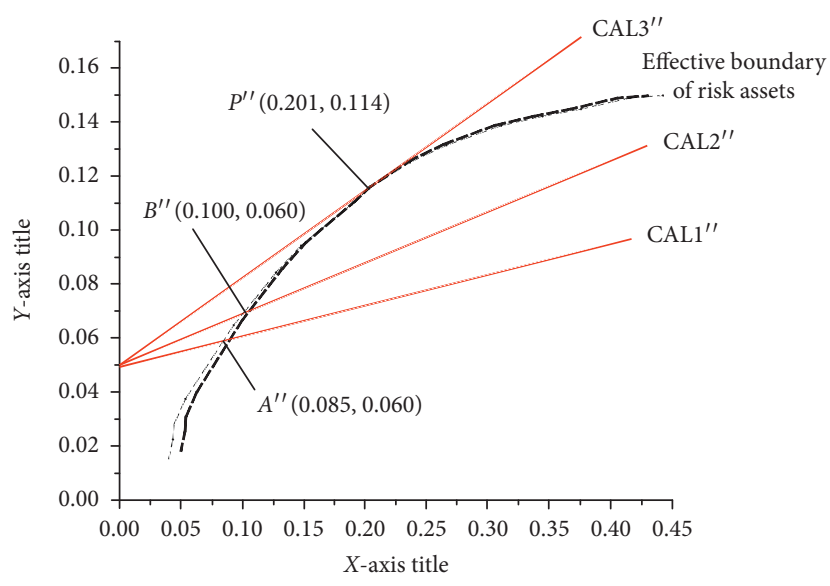

(c)

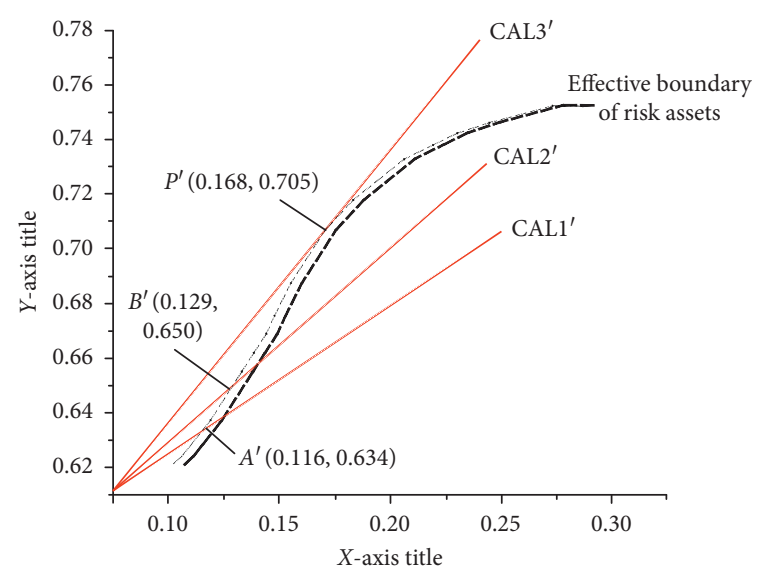

(b)

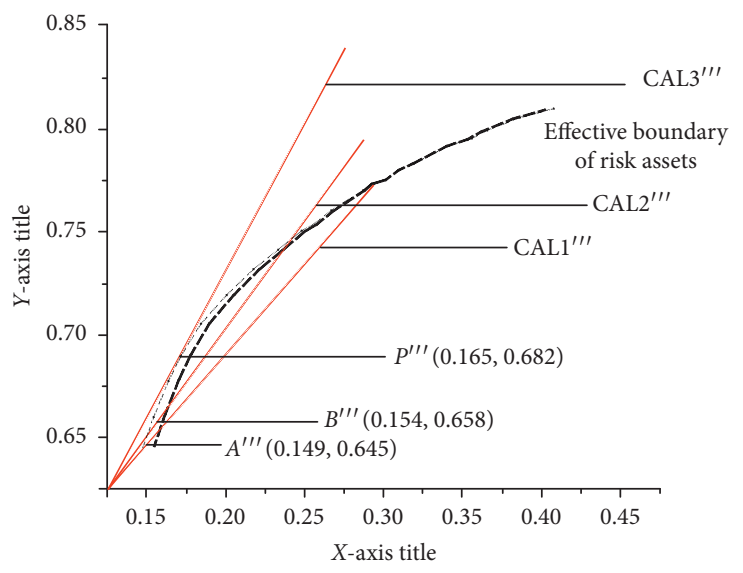

(d)

Figure 4: The optimal strategies under different risk attitudes.

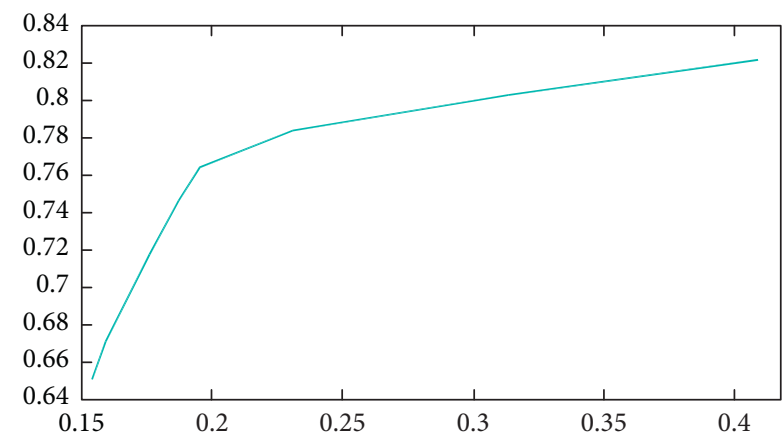

(a)

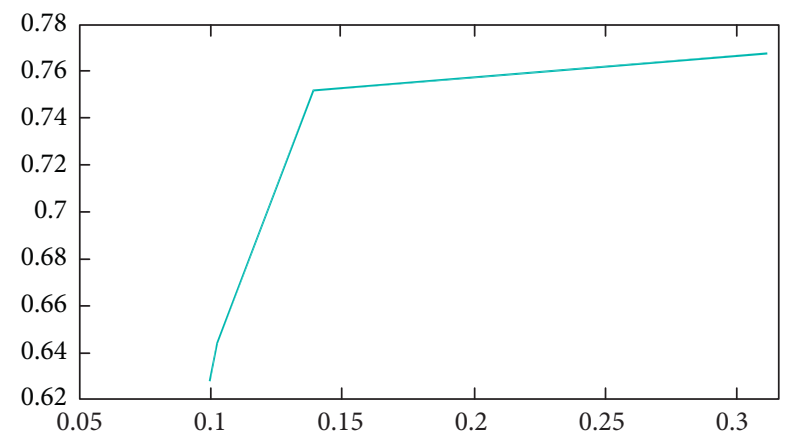

(c)

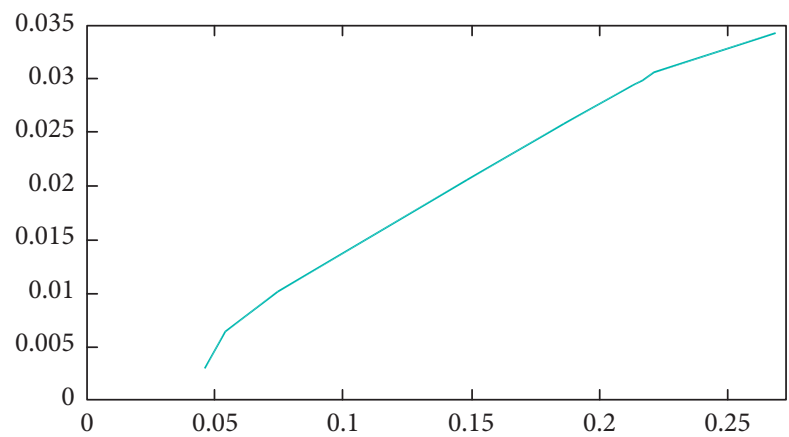

(b)

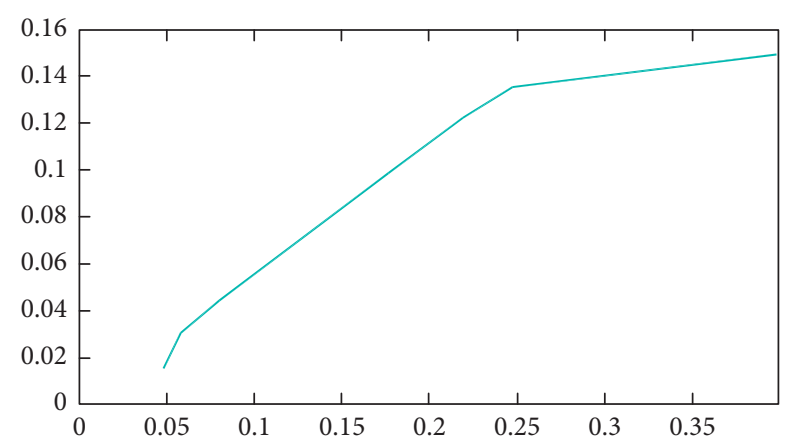

(d)

Figure 5: The value of the efficient set. 


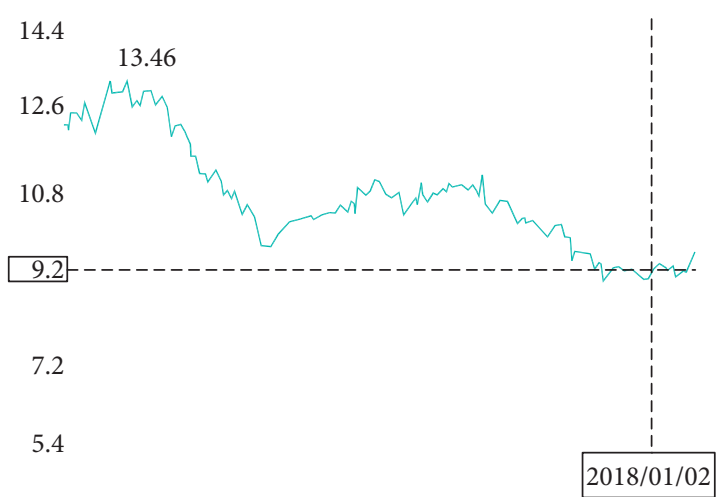

(a)

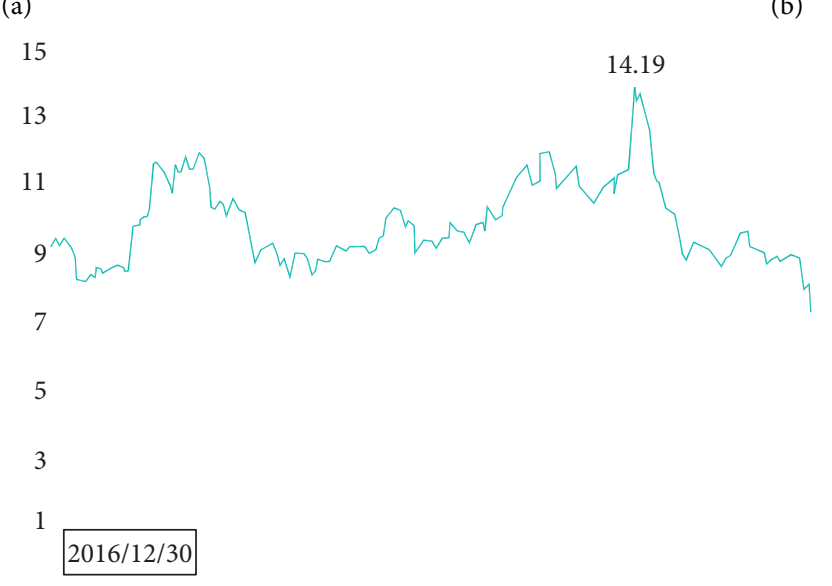

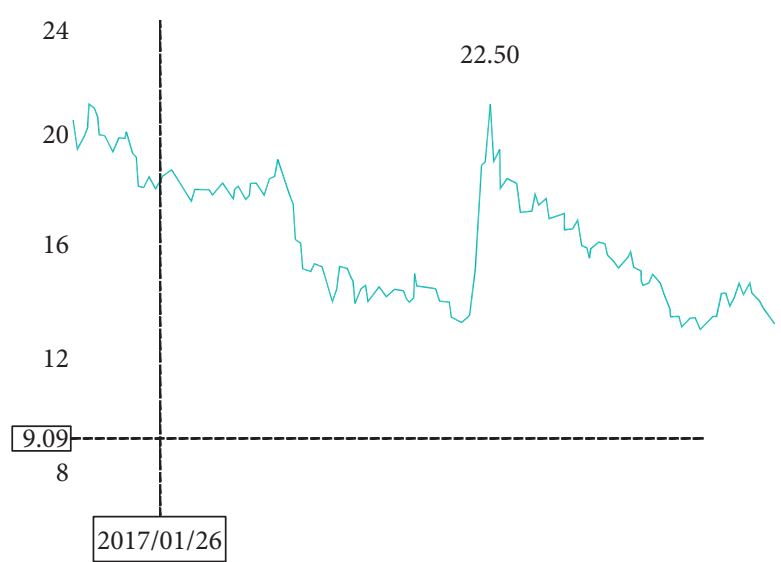

(b)

(c)

Figure 6: Actual comparison object. (a) 000719.SZ. (b) 000802.SZ. (c) 000839.SZ.

TABLe 6: The weight mean value under dynamic risk-appetite coefficient.

\begin{tabular}{|c|c|c|c|c|c|c|c|}
\hline Stock code & Mean (1) & Mean (0.75) & Mean $(0.65)$ & Mean (0.5) & Mean $(0.25)$ & Mean (0) & Mean (all) \\
\hline 000038.SZ & 0.1 & 0 & 0 & 0.11 & 0 & 0 & 0.04 \\
\hline 000156.SZ & 0.05 & 0 & 0 & 0.04 & 0 & 0 & 0.02 \\
\hline 000607.SZ & 0.04 & 0.15 & 0.06 & 0.05 & 0.02 & 0.04 & 0.06 \\
\hline $000665 . S Z$ & 0.03 & 0.06 & 0.07 & 0.04 & 0.14 & 0.21 & 0.09 \\
\hline 000673.SZ & 0.24 & 0.02 & 0.02 & 0.22 & 0 & 0 & 0.08 \\
\hline 000681.SZ & 0.16 & 0 & 0 & 0.11 & 0 & 0 & 0.05 \\
\hline 000719.SZ & 0.12 & 0.03 & 0.03 & 0.15 & 0.026 & 0.11 & 0.08 \\
\hline 000793.SZ & 0.08 & 0.42 & 0.45 & 0.06 & 0.395 & 0 & 0.23 \\
\hline 000802.SZ & 0.02 & 0 & 0 & 0.03 & 0 & 0 & 0.01 \\
\hline 000839.SZ & 0.17 & 0.32 & 0.37 & 0.18 & 0.419 & 0.64 & 0.35 \\
\hline
\end{tabular}

portfolios in different risk appetites. The results show that the portfolios considering investors who are risk-averse, risk-neutral, and risk-seeking are highly fitted to the outcomes of the double-hierarchy model, except for 000673.SZ under the portfolio with a risk appetite coefficient of 0.5. Actually, this stock's shareholders froze their accounts in 2018. Therefore, we take the second largest weight for further comparison, and the results also match the ones calculated by the double-hierarchy model. The higher and lower weights of risk-averse are 000839.SZ and 000802.SZ, and their advance-decline are $-5.16 \%$ and $-19.59 \%$, respectively. The higher and lower weights in risk-neutral are 000839.SZ and $000802 . S Z$, and their advance-decline are $-5.16 \%$ and $-19.59 \%$, respectively. The higher and lower weights in riskseeking are 000719.SZ and 000802.SZ, and their advancedecline are $-5.16 \%$ and $-19.59 \%$, respectively (see Figure 6).

Figure 5 describes the optimal portfolio point $P^{\prime}, P^{\prime \prime}, P^{\prime \prime \prime}$, and $P^{\prime \prime \prime \prime}$; the corresponding abscissa and ordinate are the risk and return in the field of investment portfolio, respectively. Each point on the efficient frontier represents the 


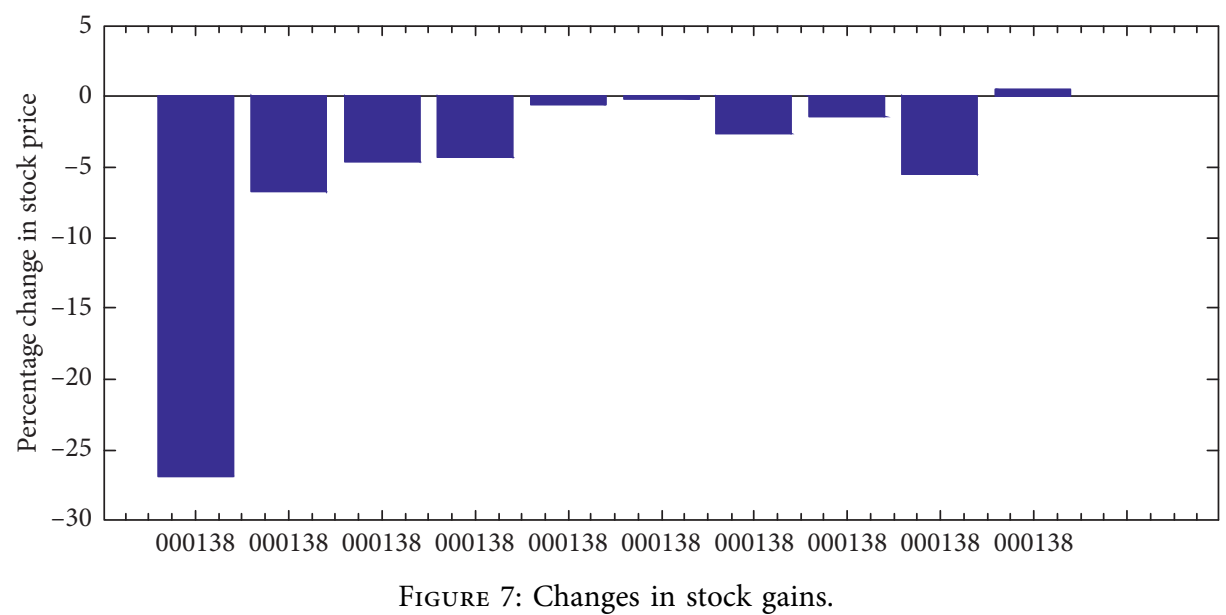

combination of returns and risks corresponding to various portfolio stocks. The portfolio securities in other points are not the best because they cannot get the maximum benefit with the least risk, and we have not drawn the corresponding frontier of inefficient investment in the lower half. The convex set is meaningless, and it is impossible for investors to reduce returns in exchange for higher risk. Table 6 shows the average optimal weights under different risk appetites.

As can be seen in Figure 7, two stocks 000038.SZ and 000156.SZ float down significantly; from the optimal weight calculated by DHMP, it can be found that the weight of these two stocks is smaller, which effectively reduces the risk of investment. The results show that this research proves the feasibility and effectiveness of the proposed double-hierarchy model with respect to the probabilistic preference.

\section{Conclusions}

Portfolio theory is playing an increasingly important role in modern economic theory. How to accurately and conveniently measure investors' risk appetite is the top priority. Because the impact factors that determine investors' subjective risk appetites are in a wide scope including time, age, and asset status, it is hard to comprehensively analyze and quantify investors' risk appetites in a portfolio calculation process. To address this issue, we take the historical simulation and probabilistic preference, MPPS, and DHMP models which take investors' risk appetites and multiple preferences into account. Therefore, optimal investment ratios can be obtained for investors to provide them with more accurate and personal investment strategies. In this paper, we have made some contributions from the perspectives of theoretical improvement and practical application. First, we provide optimal portfolio selection for different investors with diverse investment demands. Second, investors' dynamic risk appetite can be measured by probabilistic preferences. Lastly, the newly proposed method has been applied to the practical application to verify its feasibility and effectiveness.

However, there are still some limitations in the DHMP model and its application. For example, we have not given a normal form and standard for multiple-preference selection, and the time span is limited. In addition, in future research, we will attempt to provide a more reasonable preference selection with probabilistic preferences and use panel data.

\section{Data Availability}

The stock data (which were collected from the Wind database) in the empirical research used to support the findings of this study are included within the article.

\section{Conflicts of Interest}

The authors declare that they have no conflicts of interest.

\section{Acknowledgments}

This work was supported by the National Social Science Foundation of China: the ways of Financial Supervision Department to Punish Law-Breaking Institutions and the Research of Penalty Pricing (Project no. 19BJY251).

\section{References}

[1] H. Markowitz, P. Todd, G. Xu, and Y. Yamane, "Computation of mean-semivariance efficient sets by the critical line algorithm," Annals of Operations Research, vol. 45, no. 1, pp. 307-317, 1993.

[2] C. C. Y. Kwan, "Portfolio analysis using single index, multiindex, and constant correlation models: a unified treatment," The Journal of Finance, vol. 39, no. 5, pp. 1469-1483, 1984.

[3] J. Liu, "Portfolio selection in stochastic environments," Review of Financial Studies, vol. 20, no. 1, pp. 1-39, 2007.

[4] T. W. Chamberlain, C. S. Cheung, and C. C. Y. Kwan, "Optimal portfolio selection using the general multi-index model: a stable Paretian framework," Decision Sciences, vol. 21, no. 3, pp. 563-571, 2010.

[5] Y. Zhang, Q. Zeng, F. Ma, and B. Shi, "Forecasting stock returns: do less powerful predictors help?" Economic Modelling, vol. 78, pp. 32-39, 2019.

[6] A. J. Mei, "Measuring international economic linkages with stock market data," Journal of Finance, vol. 51, no. 5, pp. 1743-1763, 1996. 
[7] S. H. Penman and T. Sougiannis, "A comparison of dividend, cash flow, and earnings approaches to equity valuation," Contemporary Accounting Research, vol. 15, no. 3, pp. 343-383, 1998.

[8] R. Paul and M. Bergin, "Interest rates, exchange rates and present value models of the current account," Economic Journal, vol. 110, no. 463, pp. 535-558, 2000.

[9] S. X. Li and Y. T. Chuang, "Racing for market share: hypercompetition and the performance of multiunit multimarket firms," Advances in Strategic Management, vol. 18, no. 2, pp. 329-355, 2001.

[10] K. Reikvam, F. E. Benth, and K. H. Karlsen, "Optimal portfolio selection with consumption and nonlinear integrodifferential equations with gradient constraint: a viscosity solution approach," Finance and Stochastics, vol. 5, no. 3, pp. 275-303, 2001.

[11] M. Asai and M. Mcaleer, "A portfolio index garch model," International Journal of Forecasting, vol. 24, no. 3, pp. 449-461, 2008.

[12] J. J. Rowley and D. T. Kwon, "The ins and outs of index tracking," The Journal of Portfolio Management, vol. 41, no. 3 , pp. 35-45, 2015.

[13] D. H. Xue and Y. Z. Zhou, "Hope, fear, and aspirations," Mathematical Finance, vol. 26, no. 1, 2016.

[14] R. Israelov and M. Klein, "Risk and return of equity index collar strategies," The Journal of Portfolio Management, vol. 43, no. 4, pp. 6-10, 2017.

[15] M. R. Haley, "Shortfall portfolio selection: a bootstrap and k-fold analysis," Applied Economics Letters, vol. 52, pp. 1-4, 2020.

[16] M.-H. Liu, D. Margaritis, and A. Tourani-Rad, "Risk appetite, carry trade and exchange rates," Global Finance Journal, vol. 23, no. 1, pp. 48-63, 2012.

[17] P. Gai and N. Vause, Measuring Investors' Risk Appetite, Social Science Electronic Publishing, Rochester, NY, USA, 2005.

[18] J. N. Carpenter, "Does option compensation increase managerial risk appetite?" The Journal of Finance, vol. 55, no. 5, pp. 2311-2331, 2000.

[19] L. Bingxin, "Speculation, risk aversion, and risk premiums in the crude oil market," Journal of Banking \& Finance, vol. 23, no. 11, pp. 64-81, 2018.

[20] Y. Chi, K. S. Tan, and S. C. Zhuang, "A bowley solution with limited ceded risk for a monopolistic reinsurer," Insurance: Mathematics and Economics, vol. 91, pp. 188-201, 2020.

[21] K. Smimoua, C. R. Bectorb, and G. Jacobyc, "Portfolio selection subject to experts' judgments," International Review of Financial Analysis, vol. 17, no. 5, pp. 1036-1054, 2009.

[22] B. V. Smith and M. G. Ierapetritou, "Sensitivity-based product portfolio and design integration," Industrial \& Engineering Chemistry Research, vol. 50, no. 7, pp. 3919-3927, 2011.

[23] R. Y. Zrs and A. M. Bayoumi, "Evaluation criteria of patient and public involvement in resource allocation decisions: a literature review and qualitative study," International Journal of Technology Assessment in Health Care, vol. 33, no. 2, p. 1, 2017.

[24] W. Zhang, X. Tian, and A. Yu, "Is high-speed rail a catalyst for the fourth industrial revolution in China? Story of enhanced technology spillovers from venture capital," Technological Forecasting and Social Change, vol. 161, Article ID 120286, 2020.

[25] X. Tian, G. Kou, and W. Zhang, "Geographic distance, venture capital and technological performance: evidence from Chinese enterprises," Technological Forecasting and Social Change, vol. 158, Article ID 120155, 2020.
[26] X. L. Tian, M. Niu, W. K. Zhang, N. H. Li, and E. Herrera-Viedma, "A novel TODIM based on prospect theory to select green supplier with Q-rung orthopair fuzzy set," Technological and Economic Development of Economy, vol. 27, no. 1, pp. 1-27, 2021.

[27] I. Friend and M. E. Blume, "The demand for risky assets," American Economic Review, vol. 65, no. 5, pp. 900-922, 1975.

[28] L. P. Hansen and K. J. Singleton, "Stochastic consumption, risk aversion, and the temporal behavior of asset returns," Journal of Political Economy, vol. 91, no. 2, pp. 249-265, 1983.

[29] M. Halek and J. G. Eisenhauer, "Demography of risk aversion," The Journal of Risk and Insurance, vol. 68, no. 1, pp. 1-24, 2001.

[30] A. Nosic and M. Weber, "How riskily do i invest? the role of risk attitudes, risk perceptions, and overconfidence," Decision Analysis, vol. 7, no. 3, pp. 282-301, 2010.

[31] U. Dulleck, J. Fell, and J. Fooken, "Within-subject intra- and inter-method consistency of two experimental risk attitude elicitation," German Economic Review, vol. 16, no. 1, pp. 104-121, 2011.

[32] G. Yanling and Y. T. Dragon, “Employees' risk attitude and corporate risk taking: evidence from pension asset allocations," Journal of Corporate Finance, vol. 48, pp. 261-274, 2018.

[33] K. Weichselberger, "The theory of interval-probability as a unifying concept for uncertainty," International Journal of Approximate Reasoning, vol. 24, no. 2-3, pp. 149-170, 2000.

[34] I. Couso, S. Moral, and L. Sánchez, "The behavioral meaning of the median," Information Sciences, vol. 294, no. 294, pp. 127-138, 2015.

[35] J. Doyle and R. Green, "Efficiency and cross-efficiency in DEA: derivations, meanings and uses," Journal of the Operational Research Society, vol. 45, no. 5, pp. 567-578, 1994. 